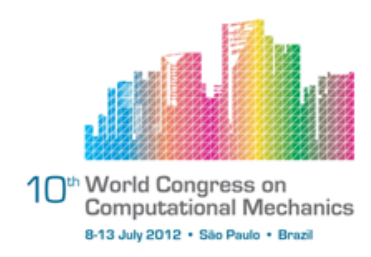

\title{
A FINITE ELEMENT PROCEDURE FOR MODELING PROGRESSIVE DAMAGE IN LAMINATED COMPOSITE SHELL STRUCTURES
}

\author{
A. Ahmed ${ }^{1,2}$, L. J. Sluys ${ }^{1}$ \\ ${ }^{1}$ Department of Civil Engineering and Geosciences, University of Technology Delft, The \\ Netherlands (A. Ahmed@tudelft.nl) \\ ${ }^{2}$ Department of Civil Engineering, N-W.F.P University of Engineering \& Technology, Pe- \\ shawar, Pakistan
}

\begin{abstract}
A mesoscopic, geometrically and physically nonlinear finite element model based on solid-like shell elements is presented for the simulation of impact damage in laminated composite structures. To model matrix cracking, a discontinuous solid-like shell element (DSLS) is utilized. A partition of unity approach is exploited to incorporate the discontinuity in the shell mid-surface, shell director and internal stretching field. This enables the element to model arbitrary propagating cracks through a finite element mesh. The element has only displacement degrees of freedom, thus avoid the need for a complicated update of rotation degrees of freedom in nonlinear applications. The model is also able to predict the buckling response of laminated composites. To model delamination phenomena, a shell interface model is developed. The model allows computationally efficient simulation of delamination and evaluation of the consistently linearized tangent stiffness matrix for large deformation problems, which is essential for convergence. To model the coupled response of matrix cracking and delamination under large deformations, a computational framework is developed. The combined modeling of matrix cracking and delamination is achieved without incorporating of additional degrees of freedom. A numerical example is presented to simulate failure resulting in matrix cracking and delamination in laminated composite shell structures.
\end{abstract}

Keywords: Solid-like shell, Laminated composites, Impact damage, Mesh independent cohesive cracking, Delamination cracking

\section{INTRODUCTION}

Fiber-reinforced composites are used in a variety of fields of engineering including aircraft, marine and defense industry. The composite structures are susceptible to impact by foreign objects. The impact on composite structures causes significant damage in terms of matrix cracking and delamination. It has been experimentally observed, e.g $[1,2,3]$, that these two damage mechanisms appear concurrently and there is a strong interaction between them. This necessitates a need for performing an adequate failure analysis on mesoscopic level. 
Failure analysis is imperative not only to determine the ultimate capacity of the structures but also to predict post-peak behavior. However, complexities exist in developing efficient numerical tools for the prediction of impact damage in laminated composites due to the presence of different complex failure mechanisms and their interactions. In several studies, e.g $[2,4,5,6,7]$, failure based or continuum damage models have been proposed for the prediction of impact damage in laminated composites. However, such models do not always perform well in localization problems and may lead to mesh dependent results.

In order to better represent localization phenomena at the interface, cohesive zone models were also explored to model delamination phenomena. [8] used interface elements with cohesive zones to model delamination phenomena in fiber reinforced laminated composites subjected to in-plane loading. [9] modeled each ply of the laminate with a single layer of solid elements. The process of delamination cracking was modeled by doubling the nodes at the interface while matrix cracking damage was modeled with continuum damage model. Although, the use of solid elements helps in obtaining the three dimensional stress field which is crucial for delamination onset and propagation, these elements tend to lock (Poisson thickness locking) and create numerical difficulties when used in thin shell applications. [10,11] presented a failure model based on solid-like shell elements and used a plasticity based approach to model matrix cracking and interface elements for delamination cracking.

The process of matrix cracking also results in strain localization and therefore continuum damage models or plasticity models create numerical difficulties in finite element computations. [12] and [13] used interface elements to model both matrix cracking and delamination to simulate the in-plane and out of plane damage in laminated composites, respectively. However, the use of interface elements requires the finite element mesh to be aligned with the crack geometry and the cracks can only grow along predefined locations.

A different approach to model cracking in a material is to use the partition of unity approach [14], which allows modeling of arbitrary propagating cracks through the finite element mesh. Such class of methods have been explored for modeling the in-plane response of composite laminates e.g $[15,16]$. For modeling mesh independent matrix cracking in laminated plates and shells, [17] presented a discontinuous shell model based on the phantom node method [18].

In this contribution a meso-scopic failure model for laminated composite plates and shells is presented. The failure model allows for arbitrary propagation of matrix cracks through the finite element mesh of solid-like shell elements. Delamination cracking is modeled using a shell interface model. A computational framework is developed in order to take into account the coupled response of matrix cracking and delamination during events of impact damage.

\section{PROGRESSIVE FAILURE MODEL}

A meso-scopic progressive failure model is presented, where each ply of the laminated composite is modeled with a single layer of solid-like-shell elements [19]. The model has been extended to incorporate higher order strains [20], which becomes important in the presence of large strains with bending deformations and shells with large bending curvatures [21]. A 
total Lagrange approach is used to simulate large deformation problems. The shell model is also able to simulate the buckling response of composites, which is crucial during events of impact, as it can substantially reduce the strength of the laminate and may trigger other failure mechanisms such as buckling induced cracking and/or delamination.

\subsection{Intra-ply damage}

To simulate matrix cracking (intra-ply damage), a discontinuous solid-like shell element (DSLS) [20] is used. The discontinuity in the shell mid-surface, shell director and more importantly in the internal stretching field is incorporated by exploiting the phantom node method [18], where an element crossed by a crack is replaced with partially active overlapping elements, see figure 1 . This enables the element to model arbitrarily propagating cracks through a finite element mesh. In [17], the discontinuous solid-like shell element (DSLS) has been successfully used to model matrix cracking in laminated fiber reinforced shell structures. The crack growth direction is taken equal to the fiber direction.

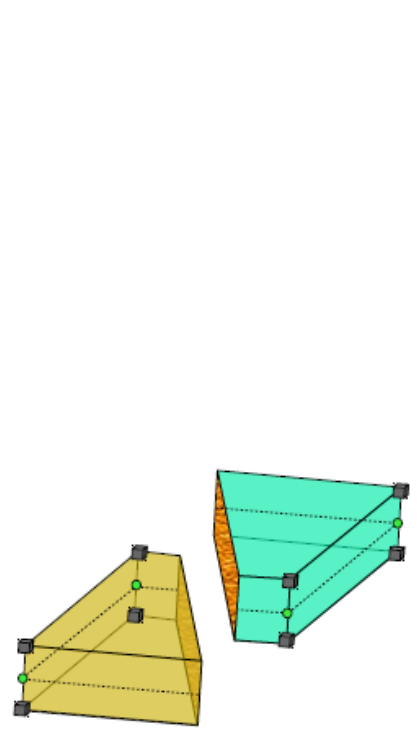

(a)

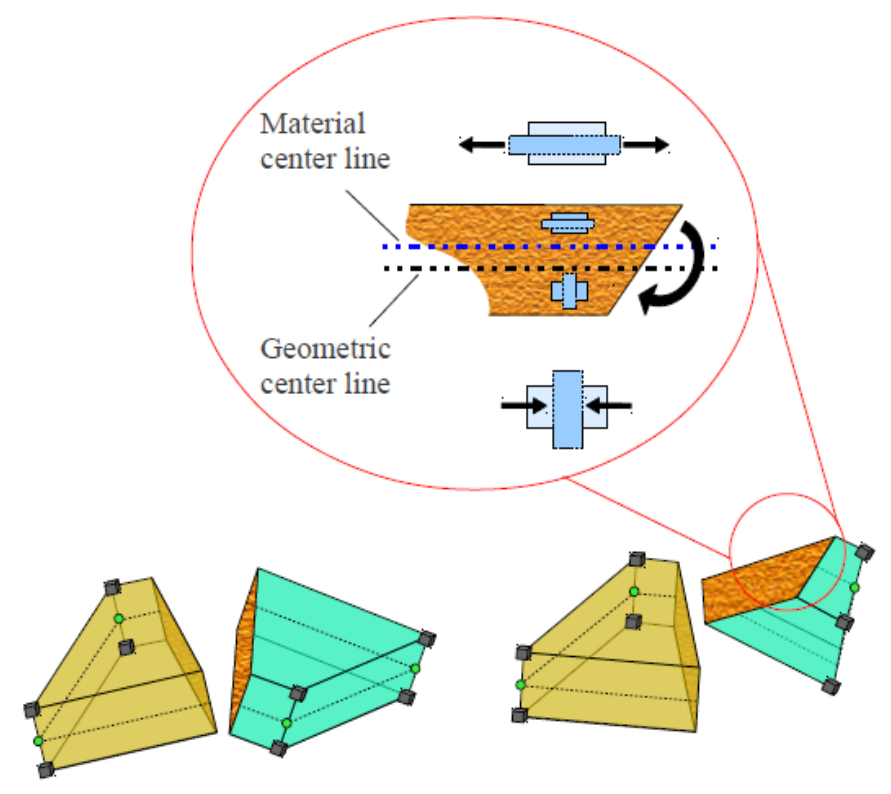

(b) (c)

Figure 1. Discontinuous solid-like shell element, (a) discontinuity in the shell mid-surface, (b) discontinuity in the shell director, (c) discontinuity in the internal stretching field due to un-symmetric bending on both sides of crack

\subsection{Inter-ply damage}

To model delamination cracking (inter-ply damage), a finite element method for delamination proposed by [22] is utilized, which is an alternative approach for modeling interfacial phenomena compared to traditional interface elements. This method allows for complete kinematic description of interfaces as opposed to interface elements. As a result it becomes 
possible to obtain a consistently linearized tangent for the interface contribution, which is important for quadratic convergence of the Newton-Raphson scheme.

\subsection{Coupled response of matrix cracking and delamination}

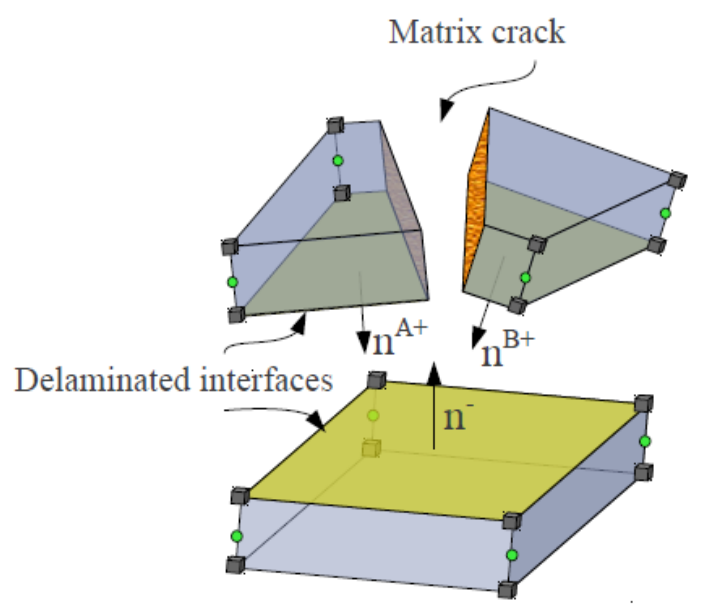

Figure 2. Progressive failure model

The presence of a matrix crack in one or both plies connected to a common interface results in a discontinuous interface (see figure 2). In order to properly take the interaction between matrix cracking and delamination into account, one or both planes of the interface have to be updated. In case of bending dominated problems, if the cracked interface is not updated (see figure 3), it will result in incorrect computation of normals to the interface and therefore will result in incorrect computation of damage. As a consequence the load capacity will be over-predicted, as is shown by [24].

In order to model an adapted interface, a partition of unity approach can be used. However, due to the fact that interfaces in our shell interface model are defined as an integral part of the continuum elements, an advantage can be taken from the database which has already been generated for matrix cracking. This will automatically update the connectivity of the elements connected to an interface. As a consequence, no additional model and degrees of freedom are added to incorporate the discontinuity in the two planes of the interface.

For integration of the interface contribution, a nodal integration scheme is used instead of a Gauss integration scheme, in order to avoid traction oscillations in the response. A traction-separation law based on the cohesive law of $\mathrm{Xu}$ and Needleman [23] is used, where the mode-mixity is taken into account by the Benzeggagh-Kenane [25] mode mixity criterion. More details on the cohesive model can be found in [24].

\section{Two ply laminated plate}

In order to investigate the performance of the progressive failure model in predicting the onset of damage, the interaction between matrix cracking and delamination and their propagation, a two ply laminated plate subjected to a quasi-static point load in the middle of the 

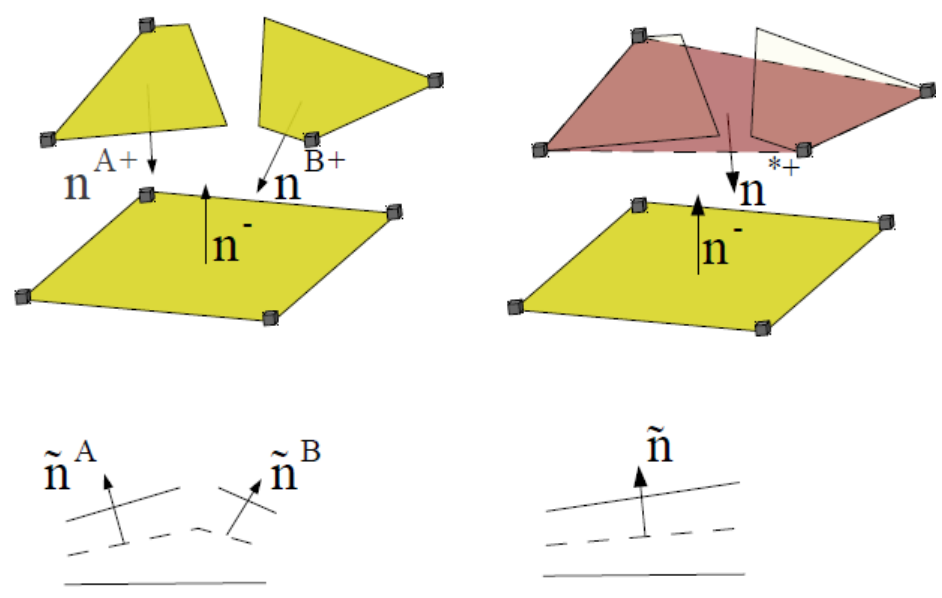

(a) Adapted interface

(b) Un-adapted interface

Figure 3. Adapted and un-adapted interfaces

plate is analyzed. The geometry of the plate is shown in figure 4 . The material properties used for the analysis are given in table 1.

Table 1. Material properties for laminated plate analysis

\begin{tabular}{|ll|ll|}
\hline Laminate properties & & Interfacial properties \\
\hline \hline $\mathrm{E}_{11}(\mathrm{GPa})$ & 140 & $\mathrm{G}_{I c}(\mathrm{~N} / \mathrm{mm})$ & 0.3 \\
$\mathrm{E}_{22}=\mathrm{E}_{33}(\mathrm{GPa})$ & 10 & $\mathrm{G}_{I I c}(\mathrm{~N} / \mathrm{mm})$ & 0.7 \\
$\mathrm{G}_{12}=\mathrm{G}_{13}(\mathrm{GPa})$ & 5 & $\mathrm{f}_{2 t}(\mathrm{MPa})$ & 50 \\
$\nu_{12}=\nu_{13}$ & 0.21 & $\mathrm{f}_{12}(\mathrm{MPa})$ & 30 \\
$\nu_{23}$ & 0.21 & & \\
\hline
\end{tabular}

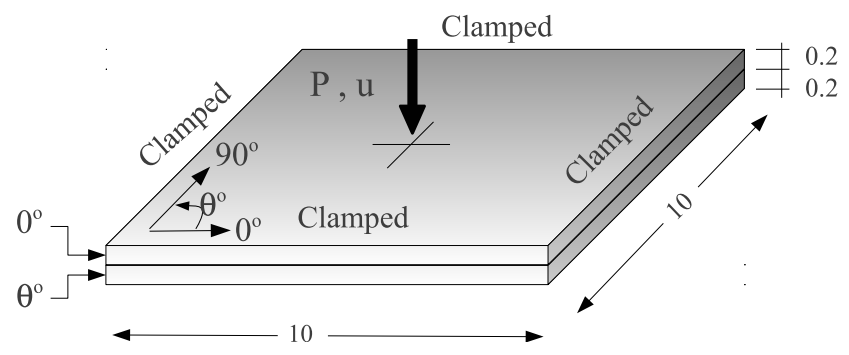

Figure 4. Plate model

For the analysis two laminate configurations are used, namely $\left[0^{\circ} / 90^{\circ}\right]$ and $\left[0^{\circ} / 75^{\circ}\right]$. Only half of the plate was modeled in the analysis purpose. It is noteworthy that the same finite element mesh is used for both the analysis, which in case of the alternative use of interface elements for modeling matrix cracks, would have required a generation of separate meshes in order to align the element edges with the crack. The analysis is performed with an uncracked plate and only single a matrix crack is allowed to initiate and grow in each ply.

Figures 5 shows the analysis results for both laminate configurations. Figures $5 \mathrm{a}$ and $\mathrm{c}$ show the delamination damage along with the matrix crack, while figures $5 \mathrm{~b}$ and $\mathrm{d}$ show the 


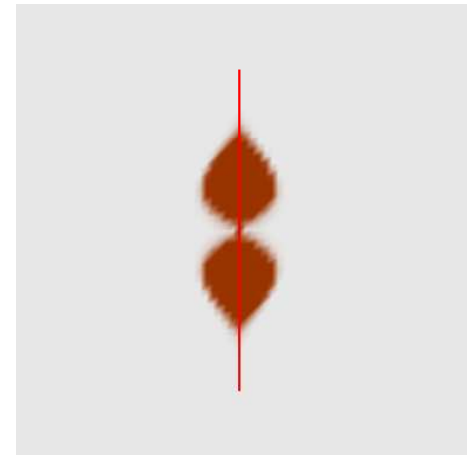

(a) Delamination damage and matrix crack (0/90)

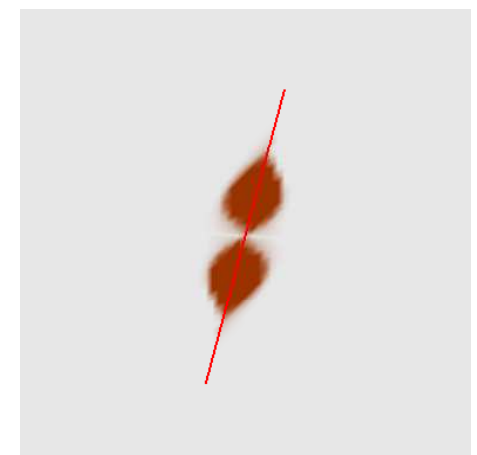

(c) Delamination damage and matrix crack $(0 / 75)$

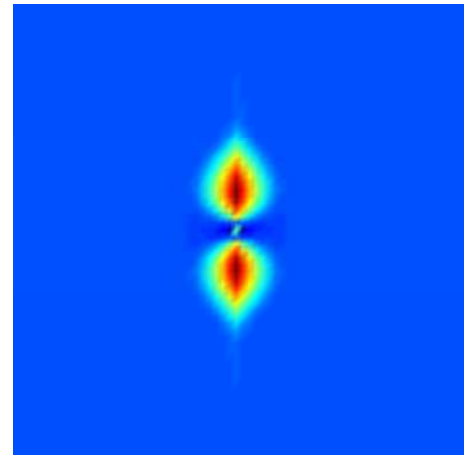

(b) Opening displacement at the interface $(0 / 90)$

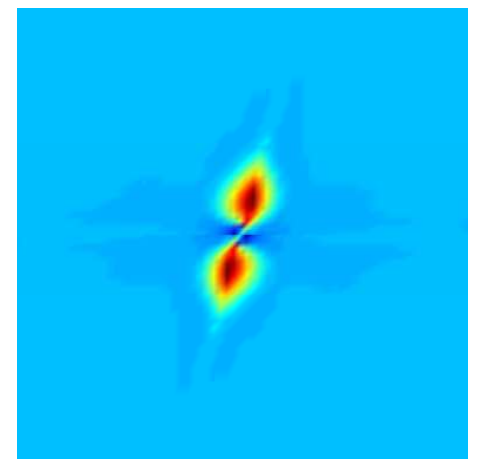

(d) Opening displacement at the interface $(0 / 75)$

Figure 5. Analysis results 
opening displacement at the interface. As was expected, a bending crack appeared in the bottom ply. Furthermore, it can be observed that the model predicted the two lobe peanut- shape delamination area very well for each laminate configuration. The delamination is aligned with the fiber direction of the lower ply along with the matrix crack, as is usually observed during experiments. Figure 6 shows a zoom at the crack for a $\left[0^{\circ} / 75^{\circ}\right]$ laminate configuration. It can be observed that the crack is not aligned with the finite element mesh.

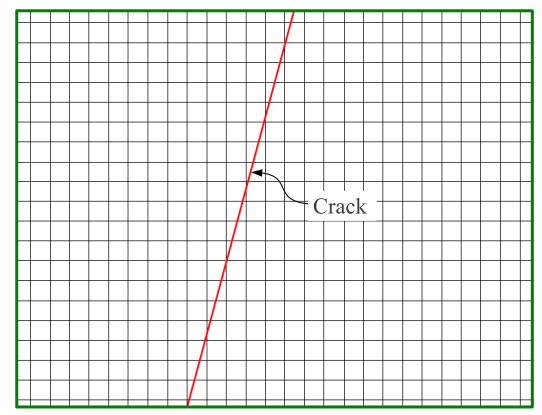

Figure 6. Zoom at crack $(0 / 75)$

\section{CONCLUSIONS}

A progressive failure model for damage in laminated composite plates is presented. The model uses solid-like shell elements which on one hand able to model thin plies of the laminate and on the other hand give a complete three dimensional state of stress. This is crucial for delamination damage. The model is capable of simulating mesh independent matrix cracking. In addition to this, a strong interaction between the matrix crack and delamination damage is captured and a peanut-shape of delamination damage zone is predicted properly for a two-ply laminate.

\section{Acknowledgements}

Financial support from N-W.F.P University of Engineering \& Technology Peshawar, Pakistan, under the HEC approved project titled "Strengthening of existing earthquake engineering center" and TU Delft, Netherlands is gratefully acknowledged. 


\section{REFERENCES}

[1] Joshi S. P., Sun C. T., "Impact induced fracture in a laminated composite". J. Compos. Mater. 19, p 51-66, 1985.

[2] Choi H. Y., Chang FK., "A model for predicting damage in a graphite/epoxy laminated composites resulting from low-velocity point impact". J. Compos. Mater. 26, p 21342169, 1992.

[3] Lammerant L., Verpoest I.,"The interaction between matrix cracks and delaminations during quasi static impact of composites”. Compos. Sci. Technol. 51, p 505-516, 1994.

[4] Hou J.P., petrinic N.,Ruiz C., Hallet S.R., "Prediction of impact damage in composite plates". Compos. Sci. Technol. 60, p 273-281, 2000.

[5] Zhao G., Cho C., "On impact damage of composite shells by a low velocity projectile”. $J$. Compos. Mater. 38, p 1231-1254, 2004.

[6] Iannucci L., Ankersen J.,"An energy based damage model for thin laminated composites". J. Compos. Mater. 66, p 934-951, 2006.

[7] Donadon M.V., Iannucci L., Falzon B.G., Hodgkinson J.M., de Almeida S.F.M.,"A progressive failure model for composite laminates subjected to low velocity impact damage". Compos. Struct. 86, p 1232-1252, 2008.

[8] Yang Q., Cox B., “Cohesive models for damage evolution in laminated composites”. Int. J. Fact. 133, p 107-137, 2005.

[9] Collombet F., Bonni J., Lataillade J.L.,"A three dimensional modelling of low velocity impact damage in composite laminates". Int. J. Numer. Methods Engng. 39, p 14911516, 1996.

[10] Hashagen F., Schellekens J.C.J, de Borst R., Parisch H.,"Finite element procedure for modelling fibre metal laminates". Compos. Struct. 32, p 255-264, 1995.

[11] Hashagen F., de Borst R., de Vries T., "Delamination behavior of spliced fiber metal laminates. Part 2. Numerical investigation”. Compos. Struct. 46, p 141-162, 1999.

[12] Wisnom M.R., Chang F.,"Modelling of splitting and delamination in notched cross-ply laminates". Compos. Sci. Technol. 60, p 2849-2856, 2000.

[13] Bouvet C., Castanie B., Bizeul M., Barrau J.J, “Low velocity impact modelling in laminate composite panels with discrete interface elements”. Int. J. Solids Struct. 46, p 2809-2821, 2009.

[14] Melenk J.M., Babuska I.,"The partition of unity finite element method: Basic theory and application". Comput. Methods Appl. Mech. Engrg. 139, p 289-314, 1996.

[15] Iarve E.V.,"Mesh independent modelling of cracks by using higher order shape functions". Int. J. Numer. Methods. Engrg. 56, p 869-882, 2003.

[16] van der Meer F.P., Sluys L.J.,"A phantom node formulation with mixed mode cohesive law for splitting in laminates". Int. J. Fract. 158, p 107-124, 2009. 
[17] Ahmed A., van der Meer F. P., Sluys L. J., "A geometrically exact, discontinuous shell model for transverse matrix cracking in composite laminates". In: ECCOMAS thematic conference on the mechanical response of composites, Hannover, Germany, p 371-378, September 2011.

[18] Hansbo A., Hansbo P., "A finite element method for the simulation of strong and weak discontinuities in solid mechanics". Comput. Methods Appl. Mech. Engrg. 195, p 35233540, 2004.

[19] Parisch H., "A continuum based shell theory for nonlinear applications". Int. J. Numer. Methods Engng. 38, p 1855-1883, 1995.

[20] Ahmed A., van der Meer F. P., Sluys L. J., "A geometrically nonlinear discontinuous solid-like shell element (DSLS) for thin shell structures". Comput. Methods Appl. Mech. Engrg. 201-204, p 191-207, 2012.

[21] Bütcher N., Ramm E., Roehl D., "Three-dimensional extension of non-linear shell formulation based on the enhanced assumed strain concept". Int. J. Numer. Methods Engng. 37, p 2551-2568, 1994.

[22] Larsson R., "A discontinuous shell-interface element for delamination analysis of laminated composite structures". Comput. Methods Appl. mech. Engrg. 193, p 3173-3194, 2004.

[23] Xu X.P., Needleman A., "Numerical simulations of fast crack growth in brittle solids". $J$. Mech. Phys. Solids 42, p 1397-1434, 1994.

[24] Ahmed A., Sluys L.J., "A three dimensional progressive failure model for impact damage in laminated composites". In preparation

[25] Benzeggah M.L., Kenane M., "Measurement of mixed-mode delamination fracture toughness of unidirection glass/epoxy composites with mixed mode bending apparatus". $J$. Compos. Sci. Technol. 56, p 439-449, 1996. 